\title{
Our commitment to climate change is dependent on past, present and future emissions and decisions
}

\author{
Markku Rummukainen* \\ Centre for Environmental and Climate Research, Lund University, Sölvegatan 37, 22362 Lund, Sweden
}

\begin{abstract}
The present day global climate change is fueled by our use of fossil fuels and land use change. The already observed warming and other distinct changes in the climate system stem from these human influences and are ongoing. Due to climate system inertia, a part of the climate system's response to this historical forcing remains to manifest itself, which it will do over time. At the same time, socio-economic forces and trends imply some amount of additional emission and land use change, which compounds our commitment to even more substantial climate change. Cumulative carbon dioxide emissions are the basic determinant of the ultimate amount of anthropogenic climate change. Climate system properties, such as climate sensitivity and the carbon cycle, and also possible initiation of non-linear changes, further shape the amount and nature of the long-term change for any set amount of greenhouse gas emissions. While a changed climate is, in practice, now unavoidable, our commitment to continued climate change can be constrained by reductions of global carbon dioxide emissions, their cessation and/or negative emissions. These alternatives have different implications for the long-term unfolding of these changes, but can all considerably reduce the possibility of very large amounts of change, the need for adaptation and responses to negative impacts.
\end{abstract}

KEY WORDS: Climate change $\cdot$ Global warming $\cdot \mathrm{CO}_{2}$ emissions $\cdot$ Climate change commitment

\section{INTRODUCTION}

The ongoing climate change manifests itself as global warming, sea level rise, significant ice loss from glaciers, mass loss from ice sheets and decreasing sea ice in the Arctic region (IPCC 2013). The principal drivers of the present day climate change are human activities, primarily greenhouse gas emissions. The resulting changes in the atmospheric composition impose a radiative forcing on the climate system, the response of which is one of an overall warming trend and other subsequent changes. The observed global mean warming over the period of 1880 to 2012 was around $0.8^{\circ} \mathrm{C}$. However, this temperature change was only a part of the climate system response. While some heat goes to cryospheric melting and land warming, the main part warms up the oceans (Rhein et al. 2013), which contributes to the concomitant sea level rise, but also slows down surface warming. The

\footnotetext{
*Corresponding author: markku.rummukainen@cec.lu.se
}

full response of the climate system to emissions unfolds over time. This means that historical emissions result in further change on top of what already has taken place and that, at any time, there is a commitment to additional change compared to what has already taken place. The amount and time evolution of the further change depends on climate system properties, namely climate sensitivity and ocean heat uptake, and also possible non-linear climate effects on the carbon cycle and ice sheets. Significantly, however, climate change ahead of us, at any given time, is affected by present and future emissions, as these effectively lock in additional long-term change (e.g. Friedlingstein et al. 2011). This is a form of socioeconomic commitment to further climate change and is due, for example, to fossil fuel related infrastructure investments with long depreciation times.

Thus, for the foreseeable future, we are committed to additional climate change. This means that for any

(C) The authors 2015. Open Access under Creative Commons by Attribution Licence. Use, distribution and reproduction are unrestricted. Authors and original publication must be credited. 
given climate stabilization target, we can effectively end up missing it well before the target level is actually exceeded. For example, the threshold to a warming of $2^{\circ} \mathrm{C}, 4^{\circ} \mathrm{C}$ or $6^{\circ} \mathrm{C}$ is effectively crossed considerably earlier than the full warming and its effects manifest themselves. Concomitantly, in the near future, we may also commit ourselves to higher risks of non-linear changes such as massive permafrost melt, which are admittedly difficult to quantify.

This paper provides a brief overview of key issues related to our climate change commitment, beyond 2100. In addition to consideration of studies which estimate the climate change commitment for some set concentration levels or emission pathways, attention is drawn to socio-economic factors. Reflections are also made on what historical emissions alone mean for our climate change commitment.

\section{COMMITTED CLIMATE CHANGE}

\subsection{Climate system response}

The amount of long-term climate change depends on the amount of carbon dioxide emissions over time and other relevant climate forcing. The relationship between the long-term warming and sustained forcing due to doubling of atmospheric carbon dioxide concentration is coined the equilibrium climate sensitivity (ECS). IPCC (2013), based on multiple lines of evidence, assessed the ECS to likely $y^{\mathbf{1}}$ be in the range of 1.5 and $4.5^{\circ} \mathrm{C}$. The range of uncertainty is wider, as it is extremely unlikely that the ECS is less than $1{ }^{\circ} \mathrm{C}$ and very unlikely that it is larger than $6^{\circ} \mathrm{C}$. Modelbased estimates of global mean sea level rise due to thermal expansion range from 0.2 to $0.6 \mathrm{~m}$ per degree of warming (IPCC 2013). Estimates of long-term mass loss from ice sheets are less well elucidated. Contributions from the Greenland Ice Sheet and Antarctic marine ice sheets could, over millennia, add up to a few meters of sea level rise for each $1{ }^{\circ} \mathrm{C}$ of warming (Ridley et al. 2010, Levermann et al. 2013, Joughin et al. 2014, Mengel \& Levermann 2014), given the exceedance of specific threshold warming levels, which are estimated to be lower for West Antarctica and Greenland than for East Antarctica.

The value of ECS is of first-order importance for climate change commitment; smaller (larger) ECS leads to smaller (larger) committed change, for a set forcing. The time-dependent warming approaches

1Extremely unlikely: 0-5\%. Likely: 66-100\%. Very unlikely: 0-10\%. (IPCC 2013) the ultimate warming level with a considerable time delay, and happens on multi-century time scales (e.g. Jarvis \& Li 2011). This is mostly due to the oceans' large heat capacity and slow turnover time. The sea level rise due to past emissions will continue even longer than what it will take for the atmospheric warming to level off.

Climate sensitivity refers to atmospheric carbon dioxide concentrations. The link from emissions to concentrations involves the global carbon cycle, which is a part of the overall climate system and constitutes an active element of the climate system response. At present, about half of the overall anthropogenic emissions are taken up in terrestrial systems and in the ocean. The longer term efficacy of these uptakes, in particular beyond the 21st century, is not certain. Still, it is the global emissions that drive the anthropogenic climate change. How they evolve is the fundamental determinant of the magnitude and also the pace of climate change.

Inasmuch as climate system inertia slows down the climate system response to increasing emissions, the same applies under mitigation. The full climate effect of emission reductions unfolds over time, and efforts to curb climate change will have their full effect with a time delay.

\subsection{Societal inertia}

Today's greenhouse gas emissions arise from the energy supply, industry, transport, buildings, agriculture, forestry and other land use. Such emissions often involve infrastructure that has a long lifetime. Power plants, for example, can operate for 30 to $40 \mathrm{yr}$ (e.g. Davis et al. 2010). This implies a 'socio-economic commitment' in the form of investments (economic commitment) to continued climate change driven by not only the historical, but also by future emissions. In the absence of alternatives of fossil fuels for energy supply, one can also speak of a societal commitment to further climate change, cf. Diffenbaugh (2013).

Davis et al. (2010) estimate the committed future emissions related to already existing infrastructure that involves burning coal, oil and natural gas, between 2010 and 2060, to around 135 gigatonnes of carbon $\left(\mathrm{GtC}_{i}\right.$ range 77 to $\left.191 \mathrm{Gt}\right)$. Together with the warming due to historical emissions, they predict a global mean warming of $1.3^{\circ} \mathrm{C}$. They note that there is an additional commitment from inter alia nonenergy sources such as agriculture. Continued investments in replacement of infrastructure that is decommissioned or in new production capacity in- 
crease the socio-economic commitment to emissions and thus to climate change. Guivarch \& Hallegatte (2011) increased the Davis et al. (2010) estimate to around $1.7^{\circ} \mathrm{C}$, by also accounting for non-emitting infrastructure such as roads and buildings, and non$\mathrm{CO}_{2}$ emissions. More recently, Davis \& Socolow (2014) noted that the committed emissions from the power sector have further increased during 2010 to 2012 , by $4 \%$ per year, due to the continued construction of coal and natural gas power plants.

Presently, energy-related investments related to fossil fuels continue (IEA 2014). The International Energy Agency (IEA) projects a long-term global mean temperature rise of $3.6^{\circ} \mathrm{C}$ under the current known energy policies and measures (IEA's New Policies Scenario; IEA 2013). IEA (2012) also highlighted that continued unabated energy-related investments involving fossil fuels through $2017 \mathrm{imply}$ a climate warming commitment of at least a $2^{\circ} \mathrm{C}$. Socio-economic trends, thus, give rise to inertia, which drives difficult-to-avoid increases in climate change commitment and adds to the climate forcing due to past emissions.

\subsection{Climate change commitment}

\subsubsection{Stabilized concentrations or zeroed emissions}

Studies on the amount of committed climate change typically involve simple climate models or Earth System Models of Intermediate Complexity. The approach has often been to consider specific stabilized (elevated) atmospheric greenhouse gas concentrations ('constant-composition commitment'), or reductions of the global emissions to zero ('zero-emissions commitment'), with more or less idealized consideration of underlying socio-economic developments. Long scenario runs with Global Climate Models (GCMs) with more specified socio-economic framing of emissions' pathways provide further insights.

The 2 approaches are fundamentally different not only in terms of their implications for global emission pathways, but also in terms of the nature of the climate change commitment. A constant-composition implies reduced, but still ongoing non-zero emissions and continued warming beyond the stabilization of atmospheric concentrations. In contrast, zeroed emissions allow for a decrease of atmospheric concentrations over time (e.g. Zickfeld et al. 2013). In both cases, the peak warming and long-term sea level rise still closely follow the cumulative emissions of carbon dioxide. The case of constant emissions ('constant- emissions commitment') has also been highlighted (Wigley 2005), but it would seem to agree least well with mainstream climate policy discussions and is not further considered here.

The climate response to changing aerosol and aerosol precursor emissions is fast both when they increase and when they decrease. The atmospheric residence time of methane is much shorter than that of carbon dioxide, whereas nitrous oxide has a longer lifetime. Thus, the commitment to climate change due to elevated aerosol levels and past emissions of methane is much shorter than the commitment to climate change due to past emissions for carbon dioxide, as well as other greenhouse gases with long atmospheric lifetimes (Matthews \& Zickfeld 2012). Changes to aerosol amounts and gases such as methane thus have a potential for relatively immediate changes to the pace of warming, but less so for long-term change. This is due to their forcing being less than that of the more long-lived gases, in particular carbon dioxide. Thus, the zero-emissions climate change commitment would follow the carbon dioxide amount. In line with the above, the constant-composition commitments follow the carbon dioxide equivalent amount, which is the same as carbon dioxide if other forcings are not in play. Fig. 1 illustrates the longer-term temperature path for constant-composition and zero-emissions, respectively.

The constant-composition case implies a residual warming trend well beyond the stabilization of concentrations (e.g. Meehl et al. 2005). It corresponds to

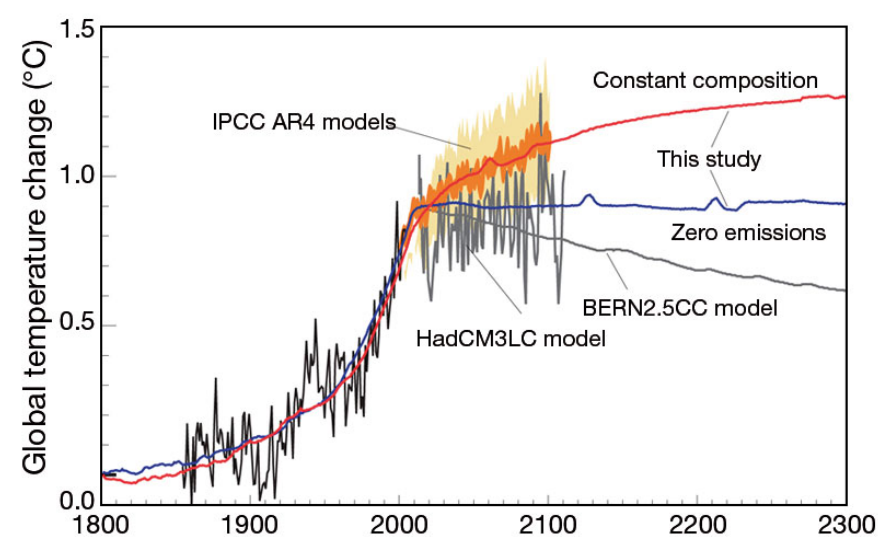

Fig. 1. Illustrative example of constant-composition (red line) and zero-emissions (blue line, grey lines; different models) global mean temperature change commitments until 2300. The orange line and the yellow shading show multimodel results as assessed in the IPCC (2007), and the black line is the observed temperature change, for reference. Figure from Matthews \& Weaver (2010). Reprinted by permission from Macmillan Publishers Ltd: Nature Geoscience 3:142-143, Fig. 1, copyright 2010 
continued emissions which, although much lower than today's, are not zero-emissions. The IPCC (2007) assessed that the residual temperature increases, after a stabilization of atmospheric concentrations, to around $0.5^{\circ} \mathrm{C}$ over the first $100 \mathrm{yr}$, and some further increase during the subsequent centuries.

If the carbon dioxide emissions are zeroed, the atmospheric carbon dioxide concentration will begin to decline very slowly due to ocean carbon sinks. However, the global mean temperature could stabilize rather than decrease, since the ocean heat uptake would also slow down (Friedlingstein \& Solomon 2005, Solomon et al. 2009). In order to achieve a reversal of the temperature trend, negative carbon dioxide emissions would be needed (Meehl et al. 2012).

Inevitability of sea level rise on multi-century time scales and longer applies for all cases above, since thermal expansion following net mixing of heat down to the deeper ocean would continue (Meehl et al. 2005, Meehl et al. 2012). Ice sheets' mass loss and other irreversible non-linear change could progress over many hundreds of years, and the regional-scale climate could continue to evolve (Gillett et al. 2011), even when the global temperature change levels off.

The equilibrium climate sensitivity (ECS) provides a way of estimating the final warming for constantcomposition commitments. The likely range of such warming, for a number of atmospheric carbon dioxide concentration levels, is depicted in Table 1. The present atmospheric carbon dioxide level of $400 \mathrm{ppm}^{2}$ corresponds to a likely long-term warming range of 0.8 to $2.3^{\circ} \mathrm{C}$ compared to preindustrial levels. This is broadly consistent with the warming in the IPCC (2007) constant-composition simulations in which the greenhouse gas concentrations were kept at the year 2000's level, and the simulations run until 2100, while also accounting for the corresponding observed warming and some residual warming beyond 2100 .

\subsubsection{Cumulative emissions and temperature rise}

The global mean temperature response in model simulations is closely related to the cumulative carbon dioxide emissions (Allen et al. 2009, Matthews et al. 2009, IPCC 2013). The global mean temperature

\footnotetext{
${ }^{2}$ The carbon dioxide equivalent level is higher, but does not necessarily reflect the long-term level due to past and present emissions, as different anthropogenic greenhouse gases and aerosols have different atmospheric lifetimes
}

change per 1000 Gt C (3670 Gt $\left.\mathrm{CO}_{2}\right)$ of carbon dioxide emissions is estimated to likely be in the range of 0.8 to $2.5^{\circ} \mathrm{C}$, for cumulative emissions up to $2000 \mathrm{Gt} \mathrm{C}$ (IPCC 2013). This is coined the Transient Climate Response to cumulative carbon Emissions, TCRE. It incorporates both the climate sensitivity and the carbon cycle, which affects the amount of emissions that resides in the atmosphere over time. TCRE is a more realistic, but also a more complicated and uncertain measure compared to ECS. Fig. 2 illustrates how the global mean temperature increase is estimated to respond to cumulative carbon dioxide emissions (IPCC 2013). The black line and the grey envelope are from simulations in which only $\mathrm{CO}_{2}$ changes. In these results, for example, a $4^{\circ} \mathrm{C}$ increase could ensue from cumulative carbon dioxide emissions in excess of $1800 \mathrm{Gt} \mathrm{C} \mathrm{(1500} \mathrm{Gt} \mathrm{C)} \mathrm{in} \mathrm{the} \mathrm{absence} \mathrm{(in} \mathrm{the}$ presence of non- $\mathrm{CO}_{2}$ emissions, here according to specific assumptions) of other anthropogenic forcings. A $2^{\circ} \mathrm{C}$ rise would correspond to around half of these emission amounts. The colored lines and the colored envelope are from studies which considered both carbon dioxide and other greenhouse gases, and thus exhibit a higher temperature response than for only carbon dioxide, for a given amount of carbon dioxide emissions.

The TCRE and ECS do not measure the same outcome. The former gives the peak warming due to the cumulative emissions. As a result of climate system inertia, the peak warming occurs sometime after a cessation of emissions, which assumes some lowering of the atmospheric concentration due to carbon sinks, before climate system inertia catches up. The latter is the long-term warming following the stabilization of carbon dioxide concentration, which would follow from reduced, but still non-zero, emissions.

Table 1. Probabilities of the long-term global mean temperature change (see Footnote 1 for probability ranges) since the preindustrial era for different carbon dioxide stabilization levels, following the IPCC (2013) assessment of the equilibrium climate sensitivity. Here, $280 \mathrm{ppm}$ is used to represent the preindustrial atmospheric carbon dioxide concentration

\begin{tabular}{|lccc|}
\hline $\begin{array}{l}\text { Carbon } \\
\text { dioxide } \\
(\mathrm{ppm})\end{array}$ & $\begin{array}{c}\text { Extremely } \\
\text { unlikely less } \\
\text { than }\left({ }^{\circ} \mathrm{C}\right)\end{array}$ & $\begin{array}{c}\text { Likely range } \\
\text { of temperature } \\
\text { change }\left({ }^{\circ} \mathrm{C}\right)\end{array}$ & $\begin{array}{c}\text { Very unlikely } \\
\text { larger } \\
\text { than }\left({ }^{\circ} \mathrm{C}\right)\end{array}$ \\
\hline 350 & 0.3 & $0.5-1.4$ & 1.9 \\
450 & 0.7 & $1.0-3.1$ & 4.1 \\
550 & 1.0 & $1.5-4.5$ & 5.8 \\
650 & 1.2 & $1.8-5.5$ & 7.3 \\
750 & 1.4 & $2.1-6.4$ & 8.5 \\
1000 & 1.8 & $2.8-8.3$ & 11.0 \\
\hline
\end{tabular}




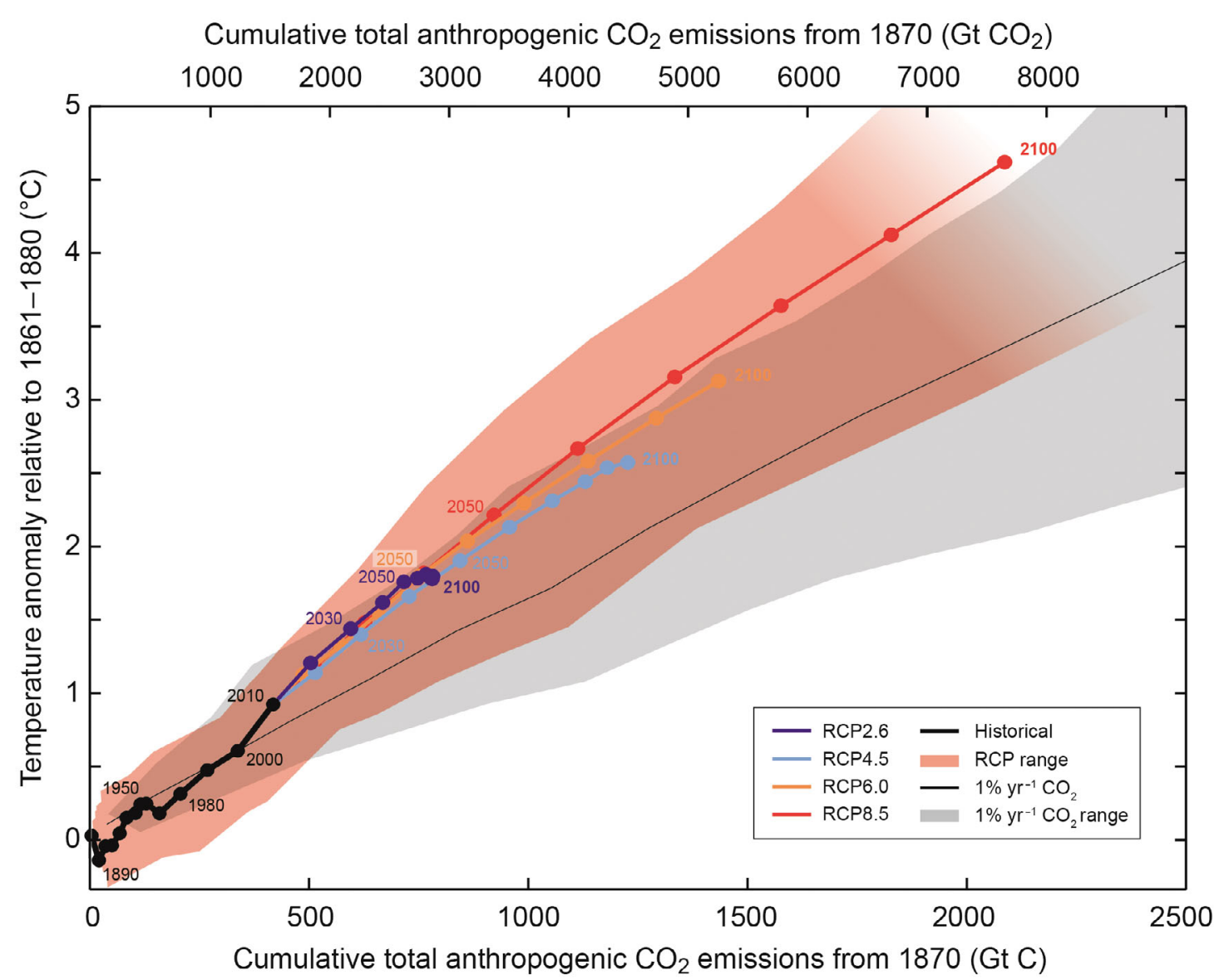

Fig. 2. Global mean surface temperature increase as a function of cumulative total global $\mathrm{CO}_{2}$ emissions from various lines of evidence. Multi-model results from a hierarchy of climate-carbon cycle models for each representative concentration pathway (RCP) until 2100 are shown with colored lines and decadal means (dots). Some decadal means are labeled for clarity (e.g. 2050 indicating the decade 2040-2049). Model results over the historical period (1860 to 2010) are indicated in black. The colored plume illustrates the multi-model spread over the 4 RCP scenarios and fades with the decreasing number of available models in RCP8.5. The multi-model mean and range simulated by CMIP5 models, forced by a $\mathrm{CO}_{2}$ increase of $1 \% \mathrm{per}$ year $\left(1 \% \mathrm{yr}^{-1}\right.$ $\mathrm{CO}_{2}$ simulations), is given by the thin black line and grey area. For a specific amount of cumulative $\mathrm{CO}_{2}$ emissions, the $1 \%$ per year $\mathrm{CO}_{2}$ simulations exhibit lower warming than those driven by RCPs, which include additional non-CO $\mathrm{C}_{2}$ forcings. Temperature values are given relative to the 1861-1880 base period, emissions relative to 1870 . Decadal averages are connected by straight lines. (Figure SPM.10 from IPCC [2013])

\subsubsection{Committed temperature change for specific emission pathways}

Another perspective on our climate change commitment is to consider alternative emission pathways, which correspond to alternative socio-economic developments. Here, projections based on 2 of the RCPs, including their extensions beyond 2100 (Representative Concentration Pathways, cf. van Vuuren et al. [2011]), are considered, the RCP2.6 and the RCP8.5 (Collins et al. 2013). These are the opposite extremes among the RCPs, and thus span the range of RCP-specific outcomes viz. the climate change commitment. The actual emission pathway in the future may of course follow yet another path.
Multi-model simulations under the aggressive mitigation RCP (RCP2.6), which features an imminent peaking of the global emissions followed by a steady decline and net negative emissions by $\sim 2070$, lead to the global temperature peaking around $1.6^{\circ} \mathrm{C}$ above preindustrial levels before 2100 , and a subsequent decline on a multi-century time scale. By 2300 , the atmospheric $\mathrm{CO}_{2}$ level would be around $360 \mathrm{ppm}$, and the residual warming around $1.2^{\circ} \mathrm{C}^{\underline{3}}$ compared to preindustrial levels.

${ }^{3}$ Range: $0.6-1.8^{\circ} \mathrm{C}$, which is constructed here from the observed warming contribution of $0.6^{\circ} \mathrm{C}$ until the CMIP5 models' reference period, and the CMIP5 multi-model projection range of $0.0-1.2^{\circ} \mathrm{C}$. See IPCC (2013), their Table 12.2 
At the other end of the scale is the RCP8.5 scenario with continued emission increases towards the end of the 21st century and stable high emissions for the next half-century, followed by a steady decrease until 2250, when the atmospheric $\mathrm{CO}_{2}$ concentration balances at $2000 \mathrm{ppm}$. The global mean temperature increase is around $4^{\circ} \mathrm{C}$ towards the end of the $21 \mathrm{st}$ century and $8.4^{\circ} \mathrm{C}^{4}$ towards 2300 , compared to preindustrial levels.

\subsubsection{Where we are now}

The observed global mean warming since the preindustrial era is around $0.8^{\circ} \mathrm{C}$, the majority of which is attributed to anthropogenic influences on the climate system, principally carbon dioxide emissions. The atmospheric carbon dioxide concentration alone stands at $400 \mathrm{ppm}$ (in addition to contributions from other greenhouse gases and aerosols to net warming) and, based on the assessment of ECS, would by itself correspond to a likely range of 0.8 to $2.3^{\circ} \mathrm{C}$ for long-term warming. A global mean warming of $3.1^{\circ} \mathrm{C}$ would be a very unlikely, but not impossible, outcome (corresponding to $\mathrm{ECS}$ of $6^{\circ} \mathrm{C}$ ).

The cumulative carbon dioxide emissions from 1750 until 2011 are estimated to be $555 \mathrm{Gt} \mathrm{C}$ (with the range of uncertainty from 470 to $640 \mathrm{Gt} \mathrm{C}$ ). The central estimate suggests a global mean warming commitment between 0.4 and $1.4^{\circ} \mathrm{C}$ based on the climate/cumulative carbon cycle response (TCRE, 0.8 to $2.5^{\circ} \mathrm{C}$ per $1000 \mathrm{Gt} \mathrm{C}$ ).

The ranges above are not the same. As mentioned earlier, the ECS and the TCRE are not comparable. The former relies on net non-zero future emissions, which add to the effective forcing due to the cumulative historical emissions, which the latter measure applies to.

Given the continuation of emissions, climate system inertia and effects of socioeconomic inertia, the long-term changes will exceed those that can be derived from the observed warming and past emissions. The possibility of a non-linear climate system response may further compound long-term climate change.

${ }^{4}$ Range: $3.6-13.2^{\circ} \mathrm{C}$, which is constructed here from the observed warming contribution of $0.6^{\circ} \mathrm{C}$ until the CMIP5 models' reference period, and the CMIP5 multi-model projection range of $3.0-12.6^{\circ} \mathrm{C}$. See IPCC (2013), their Table 12.2

\section{SURPRISES}

The considerations above do not explicitly include the effects of possible major outflow of carbon from natural sinks, such as permafrost areas or irreversible destabilization of parts of the continental ice sheets such as those in West and East Antarctica. Mobilization of permafrost carbon can be considered included in constant-composition cases, assuming that the continued anthropogenic emissions are further reduced compared to what they would be in the absence of increased carbon outflow from natural systems.

The definition of the constant-composition commitment implies that it does not as such separate between anthropogenic and induced natural emissions. The corresponding anthropogenic emissions would, however, need to be lowered, in case of weakened net natural carbon dioxide sinks. If natural carbon sinks push more carbon dioxide back into the atmosphere, the zero-emission anthropogenic commitment would provide an underestimate of longerterm climate change, as anthropogenic emissions would be compounded by natural sources. Thus, changes to the net strength of the carbon cycle would need to be compensated by lower cumulative emissions. Otherwise, the climate change commitment grows.

The long-term sea level rise due to thermal expansion is fairly well constrained. Uncertainty is greater for the possible triggering of marine ice sheet instability, which could in turn ensure a sea level rise of several meters over a long period of time, even if the global mean temperature were to stabilize or begin a slow decline, which may occur on centennial timescales following zeroed or negative emissions (see Section 2.1).

\section{DISCUSSION}

At any point in time, a part of climate change due to cumulative emissions remains to be realized, which will manifest over subsequent years. This constitutes a climate change commitment due to past emissions; a long-term and greater climate change than what has been observed so far.

Considerable global-scale emission reductions could lead to a stabilization of atmospheric concentrations of greenhouse gases, in particular carbon dioxide. This would constrain the global mean temperature trend considerably and, subsequently, other aspects of anthropogenic climate change; however, 
there would still be some residual warming, over a long period of time. Zeroed emissions would allow for a stabilization of atmospheric temperature. Negative emissions of carbon dioxide could reverse the warming trend to a cooling one.

Global emissions are still on the rise. Recent global carbon dioxide emissions from fossil fuel use, cement manufacture and land use change ${ }^{\frac{5}{5}}$ are around $10.6 \mathrm{Gt}$ $\mathrm{C} \mathrm{yr}^{-1}$. This can be coined a socio-economic commitment, which arises from the continuing investments in fossil-fuel-related energy supplies and other relevant infrastructure. During the next few years, this may effectively lock in a long-term warming of at least $2{ }^{\circ} \mathrm{C}$. Continued emissions at today's level would bring the cumulative amount up to 1000 Gt $\mathrm{C}$ after some 40 yr. Based on the cumulative carbon/climate relationship, it would mean a global mean warming commitment of $0.8^{\circ} \mathrm{C}$ to $2.5^{\circ} \mathrm{C}$ (excluding extreme outcomes). Assuming continuously increasing emissions at a rate of, for example, $2.5 \%$ per year, the same level would be accumulated after only 30 yr. Larger cumulative emissions would result in greater climate change.

The long-term temperature rise and sea level change estimates - our climate change commitment - can, for some set cumulative emissions or atmospheric concentration levels, be bounded by estimates of climate sensitivity, climate impacts on the carbon cycle, heat uptake in the ocean and possible ice sheet instability (e.g. Friedlingstein et al. 2011). As these estimates are subject to uncertainty, estimates of climate change commitment can also only be in probabilistic terms. For example, if the atmospheric carbon dioxide concentration reaches double the preindustrial level (i.e. to around $550 \mathrm{ppm}$ ), the likely assessment for long-term global mean warming is 1.5 to $4.5^{\circ} \mathrm{C}$. However, there are outcomes outside this range, including much larger values, $6^{\circ} \mathrm{C}$ being a 'very unlikely' but still conceivable outcome. For 650, 450 and $350 \mathrm{ppm}$, the 'very unlikely' outcomes are around $7^{\circ} \mathrm{C}, 4^{\circ} \mathrm{C}$ and $2{ }^{\circ} \mathrm{C}$, respectively.

The constant-composition case corresponds to continued residual emissions, although on a much lower level than today's, which may or may not be realistic depending on the time horizon. If emissions are zeroed instead, climate system inertia can counteract

\footnotetext{
${ }^{5}$ According to the Global Carbon Project (www.globalcarbonproject.org, last read 4 August 2014), the year 2012, $\mathrm{CO}_{2}$ emissions due to fossil fuel use and cement production were $9.7 \pm 0.5 \mathrm{GtC}$. Deforestation and other land use change contributed with $0.9 \pm 0.5 \mathrm{GtC}$ per year, on average, over 2003-2012
}

the level of peak warming. Negative emissions can reverse the warming trend, but not return the world to preindustrial climate conditions in any practical sense. Our commitment to continued climate change is inherently unavoidable on the multi-decadal time scale and our commitment to a changed climate is on a centennial-to-millennia time scale.

The societal view on which level of risk and harm is acceptable and, subsequently, on the necessary amount of mitigation and adaptation, is a valueladen decision. In terms of climate change related risks, the higher end of warming is more decisive from a risk perspective, as potential harm in general increases with the amount and pace of climate change. This highlights the importance of considering the full range of possible outcomes.

We can hardly affect the climate system inertia or historical emissions. In order to bound climate change in the medium-to-long term, managing the emission trends including the socio-economic commitment to continued emissions is crucial, as the climate change commitment due to past emissions is compounded by future emissions. Keeping the cumulative carbon dioxide emissions as small as possible is the key for reducing our climate change commitment. The present socio-economic trends, such as investment patterns and climate policy, however, continue to increase our climate change commitment, which will make its mark on the climate system on the centennial-to-millennial timescale. Conversely, management of these trends can over time curb the climate change commitment.

Acknowledgements. This study is a contribution to the Swedish strategic research area ModElling the Regional and Global Earth system, MERGE.

\section{LITERATURE CITED}

Allen MR, Frame DJ, Huntingford C, Jones CD, Lowe JA, Meinshausen M, Meinshausen N (2009) Warming caused by cumulative carbon emissions towards the trillionth tonne. Nature 458:1163-1166

Collins M, Knutti R, Arblaster J Dufresne JL and others (2013) Long-term climate change: projections, commitments and irreversibility. In: Stocker TF, Qin D, Plattner GK, Tignor M and others (eds) Climate change 2013: the physical science basis. Contribution of working group I to the fifth assessment report of the Intergovernmental Panel on Climate Change. Cambridge University Press, Cambridge, p 1029-1136

> Davis SJ, Socolow RH (2014) Commitment accounting of $\mathrm{CO}_{2}$ emissions. Environ Res Lett 9:084018

> Davis SJ, Caldeira K, Matthews HD (2010) Future $\mathrm{CO}_{2}$ emissions and climate change from existing energy infrastructure. Science 329:1330-1333 
Diffenbaugh N (2013) Human well-being, the global emissions debt, and climate change commitment. Sustain Sci 8:135-141

Friedlingstein P, Solomon S (2005) Contributions of past and present human generations to committed warming caused by carbon dioxide. Proc Natl Acad Sci USA 102: 10832-10836

Friedlingstein P, Solomon S, Plattner GK, Knutti R, Ciais P, Raupach MR (2011) Long-term climate implications of twenty-first century options for carbon dioxide emission mitigation. Nat Clim Change 1:457-461

Gillett NP, Arora VK, Zickfeld K, Marshall SJ, Merryfield WJ (2011) Ongoing climate change following a complete cessation of carbon dioxide emissions. Nat Geosci 4:83-87

Guivarch C, Hallegatte S (2011) Existing infrastructure and the $2^{\circ} \mathrm{C}$ target. Clim Change 109:801-805

IEA (International Energy Agency) (2012) World energy outlook 2012. OECD/IEA, Paris

IEA (2013) World energy outlook 2013. OECD/IEA, Paris

IEA (2014) World energy investment outlook. Special report. OECD/IEA, Paris

IPCC (2007) Climate change 2007: the physical science basis. Contribution of working group I to the fourth assessment report of the Intergovernmental Panel on Climate Change (IPCC). Cambridge University Press, Cambridge

IPCC (2013) Climate change 2013: the physical science basis. Contribution of working group I to the fifth assessment report of the Intergovernmental Panel on Climate Change, Cambridge University Press, Cambridge

$>$ Jarvis A, Li S (2011) The contribution of timescales to the temperature response of climate models. Clim Dyn 36: 523-531

> Joughin I, Smith BE, Medley B (2014) Marine ice sheet collapse potentially under way for the Thwaites Glacier Basin, West Antarctica. Science 344:735-738

Levermann A, Clark PU, Marzeion B, Milne GA, Pollard D, Radic V, Robinson A (2013) The multimillennial sea-level commitment of global warming. Proc Natl Acad Sci USA 110:13745-13750

Submitted: August 7, 2014; Accepted: December 5, 2014
Matthews HD, Weaver AJ (2010) Committed climate warming. Nat Geosci 3:142-143

Matthews HD, Zickfeld K (2012) Climate response to zeroed emissions of greenhouse gases and aerosols. Nat Clim Change 2:338-341

Matthews HD, Gillett NP, Stott PA, Zickfeld K (2009) The proportionality of global warming to cumulative carbon emissions. Nature 459:829-832

Meehl GA, Washington WM, Collins WD, Arblaster JM and others (2005) How much more global warming and sea level rise? Science 307:1769-1772

Meehl GA, Hu A, Tebaldi C, Arblaster JM and others (2012) Relative outcomes of climate change mitigation related to global temperature versus sea-level rise. Nat Clim Change 2:576-580

Mengel M, Levermann A (2014) Ice plug prevents irreversible discharge from East Antarctica. Nat Clim Change 4:451-455

Rhein M, Rintoul SR, Aoki S Campos E and others (2013) Observations: ocean. In: Stocker TF, Qin D, Plattner GK, Tignor M and others (eds) Climate change 2013: the physical science basis. Contribution of working group I to the fifth assessment report of the Intergovernmental Panel on Climate Change. Cambridge University Press, Cambridge

Ridley J, Gregory J, Huybrechts P, Lowe J (2010) Thresholds for irreversible decline of the Greenland ice sheet. Clim Dyn 35:1049-1057

Solomon S, Plattner GK, Knutti R, Friedlingstein P (2009) Irreversible climate change due to carbon dioxide emissions. Proc Natl Acad Sci USA 106:1704-1709

> van Vuuren D, Edmonds J, Kainuma M, Riahi K and others (2011) The representative concentration pathways: an overview. Clim Change 109:5-31

> Wigley TML (2005) The climate change commitment. Science 307:1766-1769

Zickfeld K, Eby M, Weaver AJ, Alexander K and others (2013) Long-term climate change commitment and reversibility: an EMIC intercomparison. J Clim 26:5782-5809

Proofs received from author(s): March 29, 2015 